\title{
Editorial review and proposal
}

\section{Coronary arterial patterns in complete transposition-classification in relation to the arterial switch procedure}

\author{
Joseph J. Amato, Jonathan Zelen and Joanne Bushong \\ From the Division of Pediatric Cardiothoracic Surgery, Long Island Jewish Medical Center, Schneider Children's \\ Hospital, New Hyde Park
}

\begin{abstract}
The arterial switch operation has become the standard of surgical repair for total correction of complete transposition (concordant atrioventricular and discordant ventriculoarterial connections). A standard nomenclature for classification of the numerous anatomic relationships the coronary arteries may assume, however, has yet to be universally adopted. Inconsistent use of varied nomenclatures remain an obstacle to effective communication between physicians and surgeons. In this review we offer a unified nomenclature incorporating five important relationships: the configuration of the sinuses; their location; the configuration of the arterial orifices; the pattern of branching of the major coronary arteries; and the course of each artery.
\end{abstract}

Key words: Transposition of the great vessels; arterial switch; nomenclature; classification

T

HE ARTERIAL SWITCH OPERATION IS NOW THE ESTABlished method of repair for complete transposition and related lesions. Unfavorable patterns of coronary arterial distribution may be the single most important anatomical contraindication for performing this procedure. Despite this, no specific mortality due to coronary arterial anatomy was identified as a risk factor by Quaegebeur in 1986.' The cause of most early deaths appears related to difficulties encountered during the transfer of the coronary arteries. ${ }^{2}$ If the reason for not identifying coronary arterial anatomy as a risk factor is the pre-selection of patients with favorable coronary anatomy, ${ }^{3}$ then a re-evaluation of this important concept is needed.

Most large series ${ }^{1-8}$ stress the importance of safe transfer of the coronary arteries as the essence of a good switch operation. They further emphasize the pitfalls inherent in non-recognition of the more complex coronary arterial patterns. In this review we discuss previous schemes and nomenclatures accounting for the many and varied patterns of coronary arterial distribution. We then offer the cardiologist and surgeon a simple

Correspondence to Dr. Joseph J. Amato, Long Island Jewssh Medical Center, The Schneider Children's Hospital, New Hyde Park, New York 11042, USA. Tel. 718-470-3580; Fax. 718-343-8368.

Accepted for publication 10 May 1994 system of categorization. Finally, we relate the nomenclature to the currently available surgical techniques.

\section{Historical review}

The arterial switch operation for repair of complete transposition is almost as old as surgical palliation of the lesion itself. Palliation began in 1950 with Blalock and Hanlon. ${ }^{9}$ The concept of the arterial switch dates to 1953. The erroneous concept of a simple transfer of the aorta and pulmonary trunk, which had resulted in three operative deaths, was quickly emphasized by Bailey et al, ${ }^{10}$ thus "this particular surgical approach is basically unsound since the coronary arteries nearly always arise from the right ventricular vessel." The problem with the initial procedure, obviously, was that no attempt had been made to translocate the coronary arteries during the arterial switch. That same year, Mustard and his associates ${ }^{11}$ wrote that any proposed surgical procedure which entailed switching the great arterial trunks must consider-first, the position and distribution of the coronary arteries and, second, the relative size of the great vessels. They concluded that at least one coronary artery should be translocated along with switching the great arterial trunks. Despite this advance in theory, there were no survivors of attempted operations. 
Evolution, nonetheless, continued and in 1955, Kay and Cross $^{12}$ reported a technique in which sequential transfer was performed of the pulmonary trunk to the aorta and the aorta to the pulmonary trunk. Carried out in three infants, the procedure resulted in an increase of oxygen saturation from preoperative values of $20-40 \%$ to postoperative levels of $75 \%$. All three attempts, however, proved unsuccessful due to myocardial failure. Kay and Cross concluded that it was necessary to translocate at least the left coronary artery. They postulated resolving the problem by anastomosing the left subclavian artery to the left coronary artery, but no evidence of such a procedure being attempted is documented.

Senning ${ }^{13}$ supported unequivocally the view of Bailey et $\mathrm{al}^{10}$ that these previous attempts were unsuccessful because of the failure to transfer the coronary arteries. He attempted, also in three patients, to transfer the aortic root together with the coronary arteries. This still proved unsuccessful and, because of his success with the intraatrial repair, arterial switching was abandoned.

Experiments in dogs by Bjork and Bouckaert ${ }^{14}$ using an arterial approach had similarly been unsuccessful. A similar operation, nonetheless, was clinically used with initial success by Bex and colleagues in $1979,{ }^{15}$ but later abandoned after multiple failures. Idriss and his colleagues ${ }^{16}$ in 1961 modified the procedure by transposing only a segment of the aorta containing the two coronary arteries orifices to the left ventricular outflow tract by turning it upside down and creating an anastomosis above the neoaortic valve. Two clinical attempts at this procedure failed. Experiments in small animals, by Anagnostopoulos and colleagues ${ }^{17-19}$ demonstrated survival for over an hour after transfer of the coronary arteries. These experiments included numerous procedures for the correction of complete transposition, including the current arterial switch operation. Additionally, Anagnostopoulos ${ }^{17}$ analyzed 58 autopsied hearts. This study indicated that, in 47 of the 58 hearts, coronary arterial transfer would be anatomically feasible, although no clinical attempts were made to achieve this goal.

It was Jatene ${ }^{20}$ who first obtained success with the arterial switch procedure. This was in 1975 in a child with complete transposition and a ventricular septal defect. Even following Jatene's initial success, alternatives to the arterial switch procedure continued to be explored. The Damus-Kay-Stansel procedure was independently proposed by Damus, ${ }^{21}$ Kay, ${ }^{22}$ and Stansel. ${ }^{23}$ Danielson and his colleagues, ${ }^{24}$ in 1978 , reported the first clinical success of this procedure. Aubert et $\mathrm{al}^{25}$ also in 1978, proposed and successfully created an aortopulmonary window in association with switching of the arterial trunks and baffling of the coronary arteries through the window to the new aorta.
Arterial switching in the patients with complete transposition and an intact ventricular septum, however, remained to be conquered. Absence of a ventricular septal defect rendered the left ventricle unsuitable to become the major pumping chamber. Despite a few early successful procedures by Abe et $\mathrm{a}^{26}$ and Mauck et $\mathrm{al},{ }^{27}$ most attempts at single stage repair failed. Yacoub and colleagues in $1977,{ }^{28}$ therefore, suggested the staged repair. The first stage was banding the pulmonary trunk with or without aortopulmonary shunting to increase the left ventricular muscle mass. This was followed some time later by the arterial switch procedure.

After some considerable experience with staged repairs, Yacoub in $1982^{29}$ then successfully proceeded to the arterial switch operation performed in neonates during the first few weeks of life. Castañeda in $1984,{ }^{4}$ and Quaqebeur in 1986, ${ }^{1}$ with their respective colleagues, successfully followed. The Lecompte maneuver (moving the distal aorta posteriorly through the pulmonary bifurcation) had been added to the surgical armamentarium in $1981 .^{30}$

\section{Coronary arterial patterns}

Derived from the Latin word "coronarius," coronary means crown. The coronary arteries can readily be perceived as covering the heart in crown-like fashion. ${ }^{31}$ The essence of the arterial switch procedure is translocation of the coronary arteries to the original pulmonary root, which becomes the neoaorta. Knowledge of the variations in arterial patterns is of major importance. There are at least four important relationships for the surgeon to contemplate when dealing with the aortic or pulmonary trunks and the coronary arteries.

\section{Relationship of aorta and pulmonary trunk}

There are two important features. First is the orientation of the aortic sinuses as they relate to the pulmonary sinuses. The second is the spatial relationship between the arterial trunks themselves.

Surgeons tend to recognize the standard terminology of right coronary sinus, left coronary sinus and posterior or non-coronary sinus. In the setting of complete transposition, however, pathologists have endowed the aortic sinuses with a variety of terms (Figure 1). This abundance of terminology has led to confusion within the literature. No standard convention or nomenclature relating the aortic and pulmonary trunk in the context of right-left coordinates of the body has been recognized. The "normal" relationship, as well as the usual relationship of the sinuses in complete transposition, are shown in Figure 1. We favor the later nomenclature of Gittenberger-de Groot et $\mathrm{al}^{32}$ for designating the sinuses as "Sinus 1 " and "Sinus 2." 
NORMAL HEART

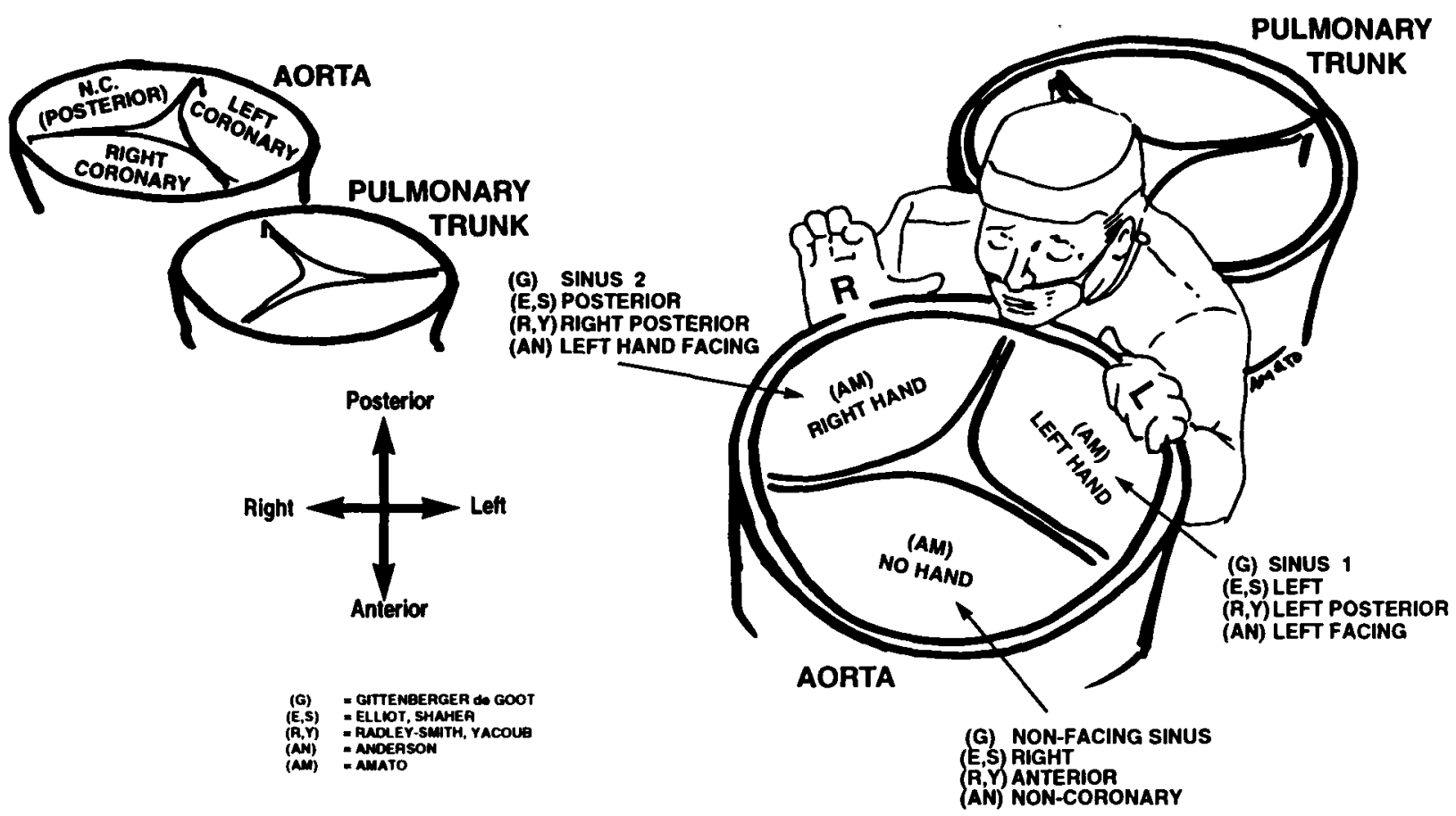

Figure 1. Summary of the various nomenclatures used to describe the anatomic position of aortic sinuses in complete transposition.

For a descriptive approach, we prefer to have the surgeon sitting in or on the pulmonary trunk (the neoaorta) facing the aorta (the neopulmonary trunk) with the left hand on the left-sided sinus and the right hand on the right-sided sinus (Figure 2). ${ }^{33}$ The facing sinuses can then be designated simply as right handed and left handed. The beauty of this approach is that it is independent of the variable relationship of the arterial trunks.

Elliot et al ${ }^{34}$ and Gittenberger-de Groot et al ${ }^{32}$ have argued for three basic spatial relationships between the arterial trunks. Designated as oblique, side-by-side or frontal, these groupings account for the vast majority of cases. Less common examples of the aorta anterior and to the left, or the aorta posterior and to the right, should also be anticipated. Irrespective of these relationships, when seen by the surgeon from the neoaorta, one sinus is always to the left hand and the other to the right hand. The third sinus is the no-handed sinus (Figure 2).

Sinuses and commisures of aortic and pulmonary trunks The alignment of the commissures of the two arterial valves is also of major surgical significance. The study of Gittenberger-de Groot et a ${ }^{32}$ showed that the "handed" sinuses in the aorta faced the pulmonary trunk in all their cases. Alignment of the commissures was perfect in two-thirds of these cases, but slightly deviated but adequate for coronary arterial transfer in one-sixth. In 20 of 103 cases $(19.4 \%)$, nonetheless, major nonalignment was observed. The authors suggest that this coronary sinusal malalignment should alert the surgeon to a potentially difficult re-implantation of the coronary arteries, and may predicate the need for an alternative operative procedure.

\section{Coronary patterns recognized by echocardiography and angiography}

Most patients can proceed to surgical correction of complete transposition based on echocardiographic data without the need for cardiac catheterization. ${ }^{35}$ Balloon septostomy, if needed, can be performed in the Cardiac Intensive Care Unit. Angiography can be performed to visualize the aorta and pulmonary trunk, and to determine pressures. There is agreement that angiography in the aortic root is frequently inadequate for display of the coronary patterns, although variants may sometimes be visualized. ${ }^{36,37}$ Echocardiography demonstrates the coronary patterns more frequently. ${ }^{38}$ Neither echocardiography nor angiography can be relied upon entirely to demonstrate those patterns of coronary arteries which may be difficult to transfer at surgery. Magnetic resonance imaging and transesophageal echocardiography have not been shown to be superior to the conventional ultrasonic methods in 


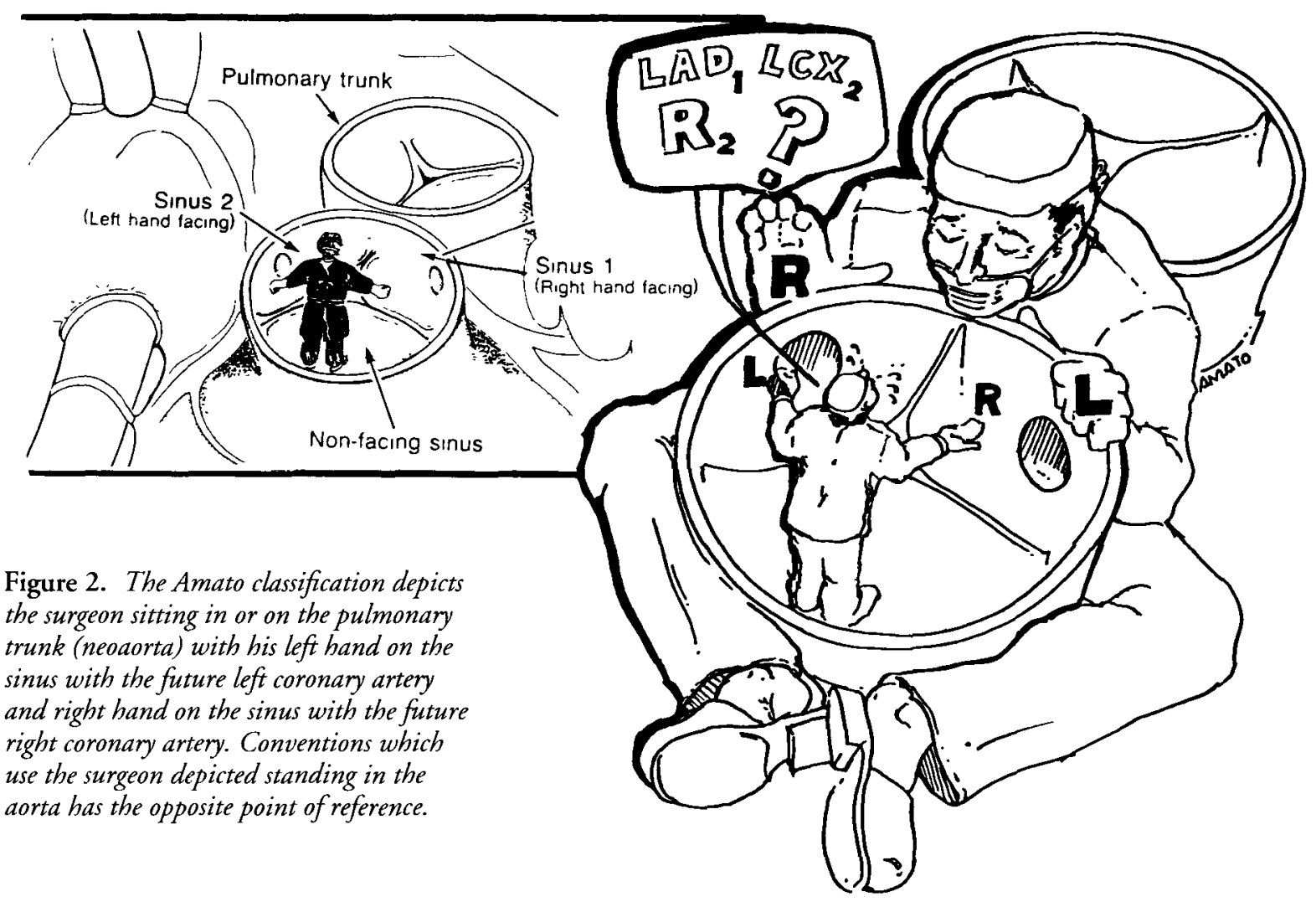

demonstrating these patterns. ${ }^{39}$ Thus, while surgical reports in 1989 and 1990 frequently stressed the use of angiography on all patients, echocardiography is currently the new gold standard. The decision concerning the transfer of coronary arteries, nonetheless, can readily be made in the operating room.

\section{Classification of patterns of coronary arterial distribution}

A thorough understanding of the anatomical variations of coronary arteries is essential for consistent successful translocation of the coronary arteries. The morphology of the coronary arteries in complete transposition, however, has become difficult to describe because numerous authors $32,34,40,41,42-45$ have each accounted for the patterns they encountered using their own classifications of differing complexity.

Early classifications were primarily morphological and were derived in the pre-Jatene era, prior to the widespread adoption of the arterial switch operation. ${ }^{34,40,42}$ The later era of classification (post-Jatene era) has tended to concentrate on surgical considerations. ${ }^{532,41.43}$ The literature, nonetheless, remains abundant with accounts of surgical procedures utilizing a mixture of classifications, thus rendering the descriptions somewhat confusing to the reader.

\section{THE PRE-JATENE ERA OF CLASSIFICATION}

One of the first descriptive classifications was that of Rowlatt. ${ }^{42}$ She observed five distinct patterns of coronary arterial distribution in 59 hearts with an intact ventricular septum and six distinct patterns in 23 hearts with a ventricular septal defect (Figure 3).

Elliott et $\mathbf{a l}^{34}$ used as the basis of their system the relationships of the arterial trunks, giving oblique, sideby-side and frontal patterns. Each then had subgroups according to the noted patterns of distribution of the coronary arteries (Figure 4).

The third major classification of this era was that of Shaher and Puddu ${ }^{40}$ (Figure 5). Nine major groups were recognized, with a total of 18 subtypes, producing a classification that is virtually impossible to commit to memory.

\section{THE POST-JATENE ERA OF CLASSIFICATION}

In 1975, the surgical world was awakened to the feasibility of the arterial switch procedure. ${ }^{20}$ With the surgical success came new schemes for classification. Yacoub and Radley-Smith introduced a simple surgical classification. ${ }^{41}$ They encountered five types in a series of 18 patients (Figure 6). Type $A$ was found in 11 patients. In this group the openings of each coronary 

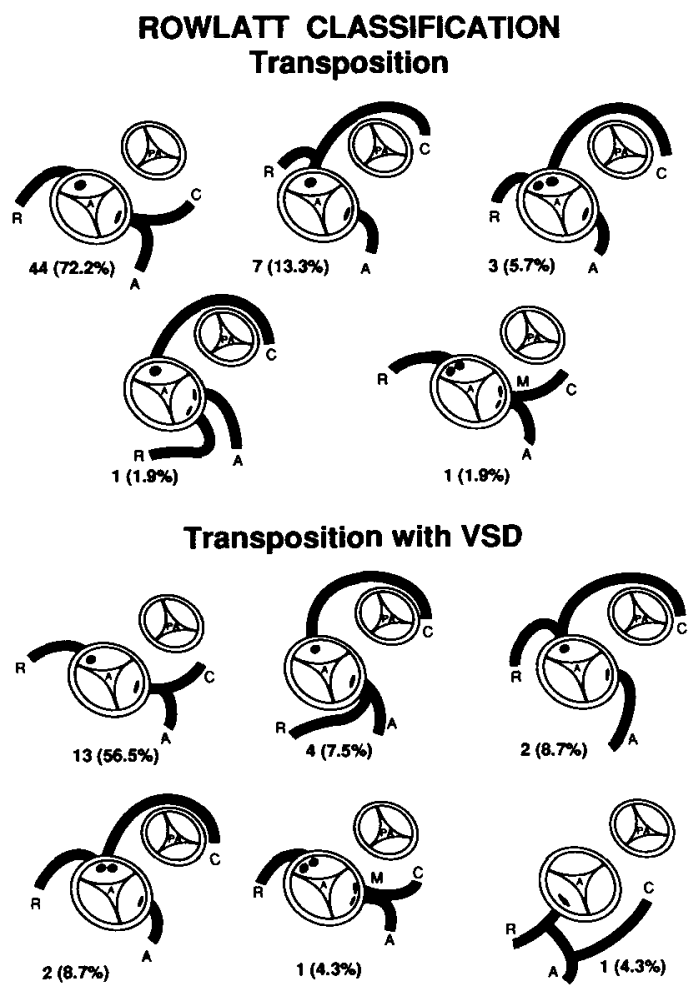

Figure 3. The Rowlatt classification with and without concomitant ventricular septal defect. Numbers indicate the total number of cases (Percentage of the total cases).

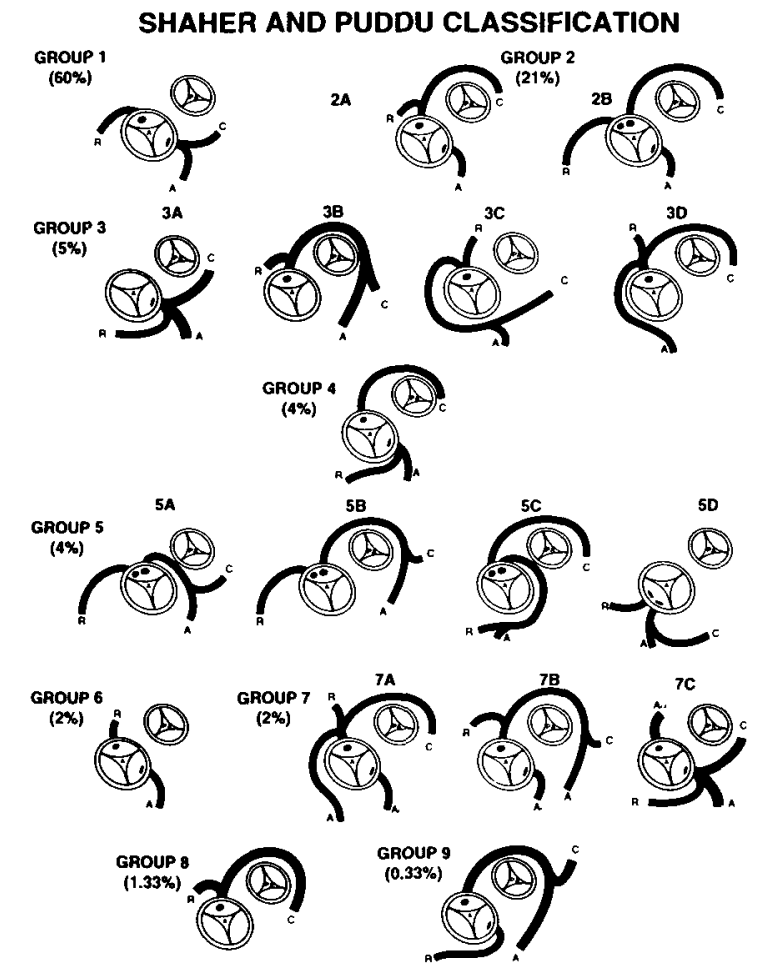

Figure 5. The Shaher and Puddu classification by group and subgroup in complete transposition.

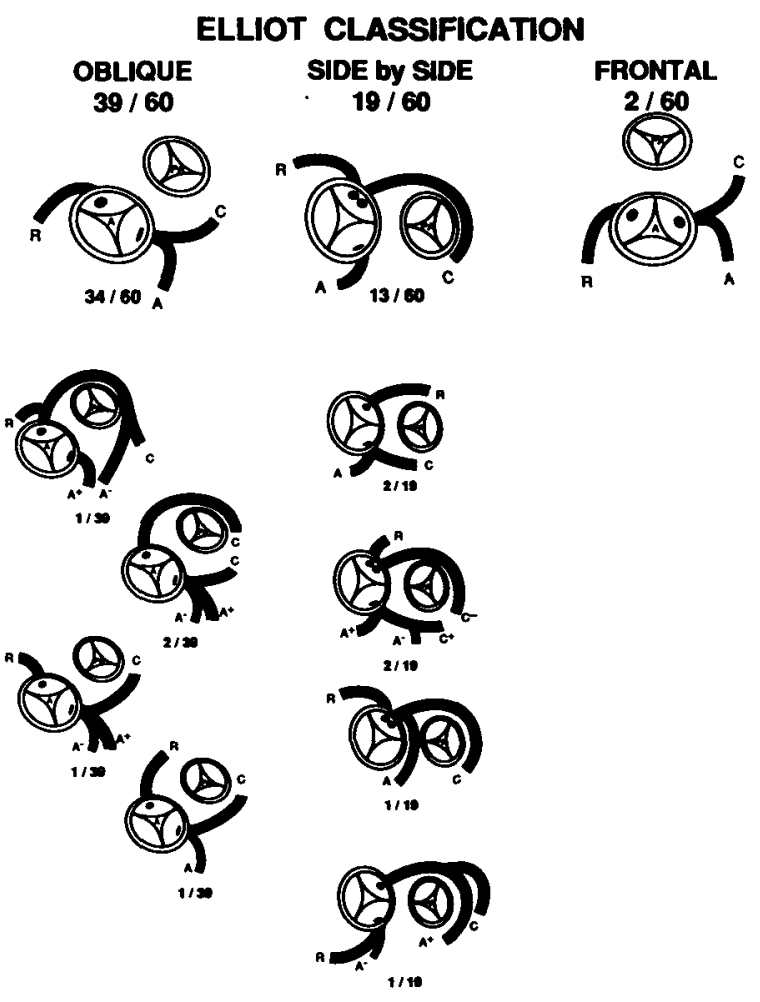

Figure 4. The Elliott classification. Numbers indicate the total number of cases.

\section{YACOUB AND RADLEY-SMITH CLASSIFICATION} Clinical Series
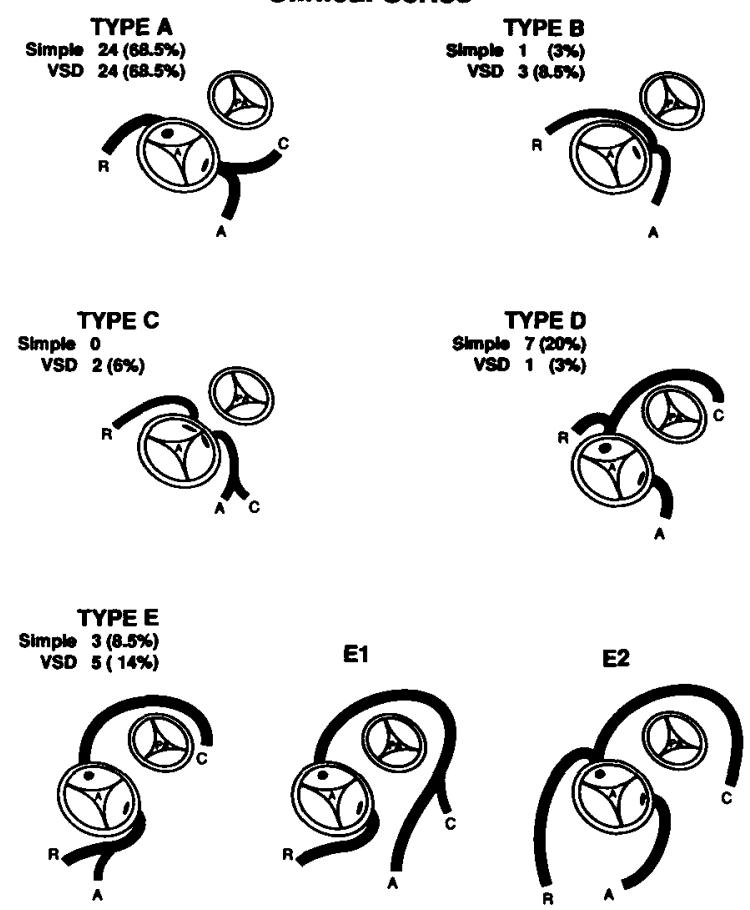

Figure 6. The Yacoub and Radley-Smith classification by type with and without concomitant ventricular septal defect. 


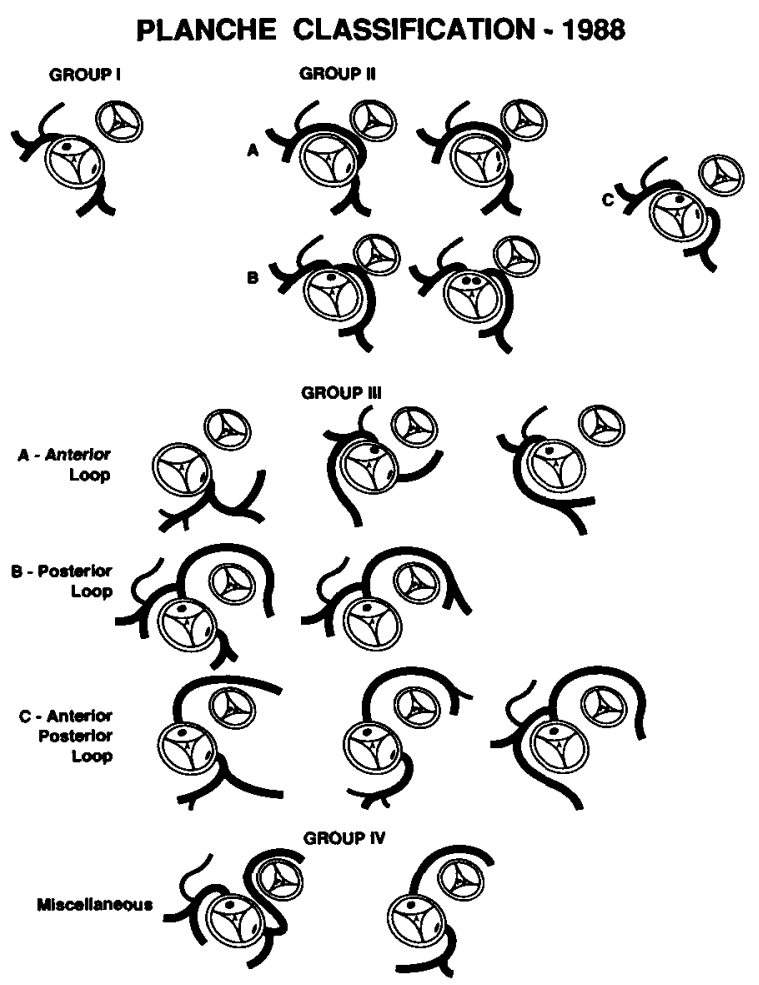

Figure 7. The Planché classification by group and subgroup.

artery are located centrally in the sinus. The right artery courses directly to the right atrioventricular groove, while the left branches into the circumflex and anterior descending arteries. Type $\mathrm{B}$ was found in two cases. The left and right arteries originated from a single orifice either in the posterior left or posterior right sinus (sinus 1 or sinus 2), then branched into left and right coronary arteries. Type $\mathrm{C}$, found in one patient, showed two coronary orifices originating close to each other at the facing commissure which then branched as in Type A. Type $\mathrm{D}$, found in three patients, is similar to Type $\mathrm{A}$ except that the circumflex artery arises from the right artery and curves posteriorly around the pulmonary trunk. Type E was unusual, and was characterized by origin of the circumflex artery from the right posterior sinus (sinus 2). Another coronary trunk arises from the left posterior sinus (sinus 1) and divides into a right main and left anterior descending arteries.

The problem with this classification is that its very simplicity derives from the fact that it is based on only 18 cases. This means it does not include all the anatomic variants which can be, and had already been, encountered.

The classification of Yacoub and Radley-Smith, was modified by Planché et al in $1988 . .^{5}$ They divide the coronary arterial patterns into four groups (Figure 7). In group I, which comprised $71 \%$ of their patients, there are two orifices from the facing sinuses with a normal

\section{GITTENBERGER de GROOT CLASSIFICATION}
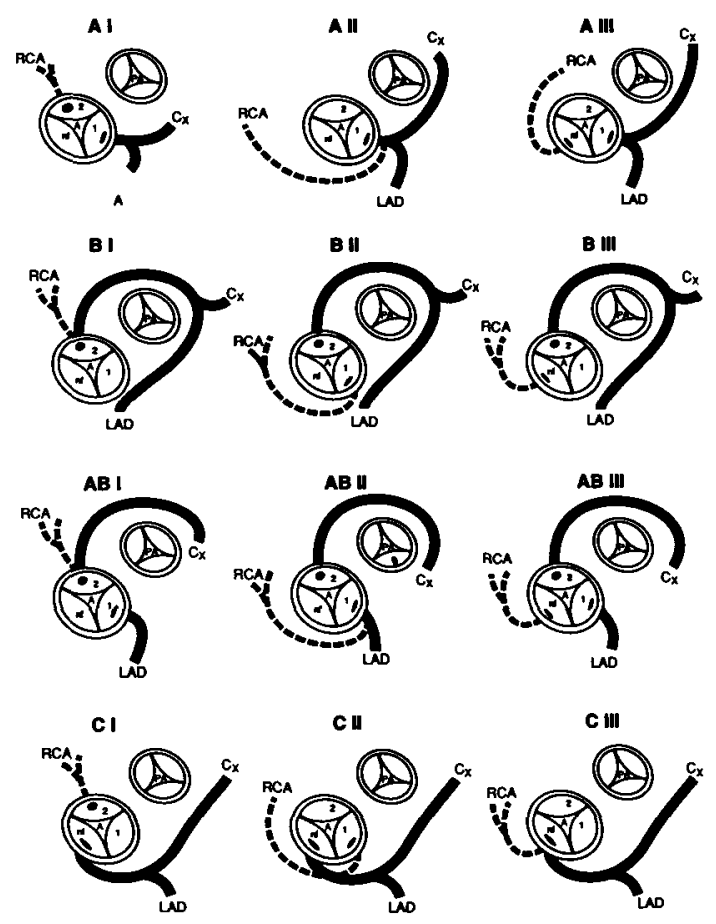

Figure 8. The Gittenberger-de Groot classification by group and subgroup.

course of the right and left coronary arteries. Group II has five subtypes and includes one or two orifices from either one or two facing sinuses and is characterized by either one or both arteries coursing between the aorta and pulmonary trunk (6.9\%). Group III is divided into three subgroups with seven subtypes. It includes those with one or two orifices arising from one or two facing sinuses, with combinations of arteries looping in front of or behind either the aorta and/or pulmonary trunk $(21.3 \%)$. The final group is a combination of groups I to III. The French team states that other classifications have been either incomplete or too complex for decision-making with regard to coronary arterial transfer. Their classification attempts to take into account the origins and initial courses of the coronary arteries.

Gittenberger-de Groot et $\mathrm{al}^{32}$ analyzed a large series of patients. In their study of 103 personally autopsied cases, correlations were made with cases previously reported (Figure 8). This enabled the authors to assert that all patterns of coronary arteries should permit translocation without great surgical difficulties. The classification, nonetheless, is by no means simple. The sinusal origin of the left coronary artery determines the existence of groups A, B, AB and C. In group A, the left artery derives from sinus 1 , while in group $B$ it is from sinus 2 . In group $A B$, the left anterior artery comes from 
SMITH CLASSIFICATION Dual Sinus Origin
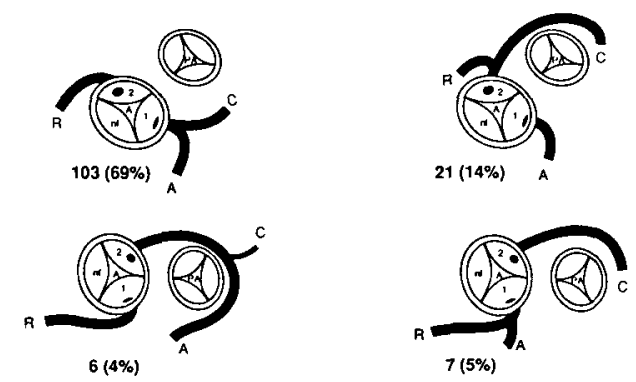

Single Sinus Origin

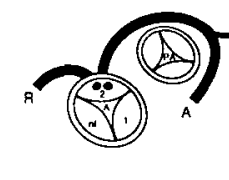

$3(2 \%)$

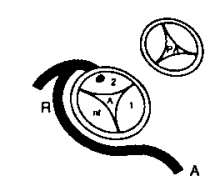

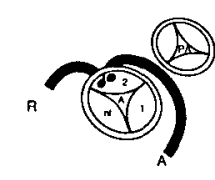

$2(1.5 \%$

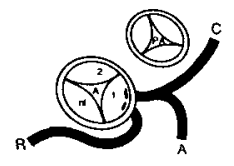

Figure 9. The Smith classification. Numbers indicate the total number of cases. Percentage of the total cases is depicted in parenthesis.

sinus 1 and the circumflex artery from sinus 2 . In the very rare type, $C$, the left artery comes from the nonfacing sinus. The origin of the right coronary artery then forms the subsets I, II and III. Origin of the artery from sinus 2 gives subset I, from sinus 1 , subset II and from the non-facing sinus gives subset III. There are, therefore, 12 combinations of arterial origin theoretically possible in this classification.

Recently, Kirklin ${ }^{45}$ commented on a proposal from Yamaguchi and colleagues ${ }^{46}$ that a mixed classification derived from the concepts of Yacoub and Radley, ${ }^{41}$ Smith et al, ${ }^{43}$ and from Shaher and Puddu, ${ }^{40}$ was of most clinical value. Kirklin ${ }^{45}$ believed that all their proposals could be described in the inclusive and simpler classification of Gittenberger-de Groot et al. ${ }^{32}$ Yamaguchi responded that the Leiden classification was not sufficiently flexible to handle all coronary arterial patterns. He described supplementary rules which could modify the Leiden system. ${ }^{46}$

Smith et $\mathrm{l}^{43}$ had proposed one of the most comprehensive classifications (Figure 9). This approach adheres closely to the Leiden convention (Gittenberger-de Groot et $\mathrm{al}^{32}$ ) but amplifies it further. The first salient feature is that the observer, standing in the non-coronary sinus of the aorta, has his right hand facing the left-

sided sinus (or sinus 1) and the left hand is facing the right sinus (or sinus 2). This permits these sinuses, irrespective of the relationships of the arterial trunks to be named as right-hand or left-hand facing sinuses, obviating the need to remember which of the two is number 1 or number 2 . The convention in this respect, nonetheless, suffers a major disadvantage. The righthand sinus is usually left-sided and gives rise to the left coronary artery, in contradistinction to the pattern encountered in the normal heart. ${ }^{47}$ This deficiency can readily be corrected, as we have already suggested (Figure 2), by viewing the sinuses from the non-facing sinus of the pulmonary trunk which, after the switch procedure, will become the aorta. We prefer, therefore, that rather than the surgeon standing within the aorta looking posteriorly, the surgeon should be sitting in or on the pulmonary trunk looking forward. This concept was presented at the Fourth International Symposium on Cardiac Surgeryin Rome, May of 1991. ${ }^{33}$ Smith and her colleagues accept that this modification is a major improvement upon their initial concept (personal communication, January 21,1994$).{ }^{48}$ The second step in the approach of Smith et $a^{43}$ is to designate any coronary artery arising from any aortic sinus which gives rise to one or more of the three major coronary arteries (the right coronary, anterior descending and the left circumflex arteries) as a "main coronary artery." Separate small arteries arising from separate orifices are considered to be accessory arteries. Within the hearts they examined, all coronary arteries arose from the facing sinuses. When at least one main coronary artery arose from each facing sinus, this was described as dual sinusal origins. In contrast, when the main coronary arteries arose from only one of the facing sinuses, either from a single orifice or multiple orifices, this was designated as single sinusal origin. Of the 148 patients they examined, $92 \%$ could be classified into four major patterns with dual sinusal arterial origins. The coronary arteries took origin from a single sinus in eleven other patients (8\%) (Figure 9). Although, in the series of Smith et al, ${ }^{43}$ there were no origins of a coronary artery from the non-facing sinus, two such origins have been reported in the collected series of Gittenberger-de Groot et al. ${ }^{32}$ One case was described by Elliot et $\mathrm{al}^{34}$ and the other by Shaher and Puddu. ${ }^{40}$

Another major emphasis by Smith et $\mathrm{al}^{43}$ was the origin and route of the sinus nodal artery. The course of this artery is markedly variable. It was directed from the anterior surface of the right or left artery towards the intra-atrial groove in all cases but for one. It originated from the right coronary artery in $67 \%$ and the left coronary artery in $33 \%$ of cases. In seven percent of the cases, the sinus nodal artery took origin from a separate orifice within the same sinus as a major coronary artery. This is important, since two orifices of two coronary 


\begin{tabular}{||c|c|c|c|c|}
\hline $\begin{array}{c}\text { SINUS } \\
\text { CONFIGURATION }\end{array}$ & $\begin{array}{c}\text { SINUS } \\
\text { LOCATION }\end{array}$ & $\begin{array}{c}\text { ORIFICE } \\
\text { CONFIGURATION }\end{array}$ & $\begin{array}{c}\text { CORONARY } \\
\text { ARTERY BRANCH }\end{array}$ & $\begin{array}{c}\text { CORONARY } \\
\text { ARTERY COURSE 9 }\end{array}$ \\
\hline $\begin{array}{c}\text { Single Sinus (SS) } \\
\text { Dual Sinus (DS) }\end{array}$ & $\begin{array}{c}\text { Right Hand Sinus (rhs) } \\
\text { Left Hand Sinus (Ihs) } \\
\text { No Hand Sinus (nhs) }\end{array}$ & $\begin{array}{c}\text { Single Orifice(o) } \\
\text { Double Orifice (oo) } \\
\text { Triple (ooo) }\end{array}$ & R + lor L + lor C & $\begin{array}{c}\text { (A) or (P) or (B) } \\
\text { and/or (M) }\end{array}$ \\
\hline
\end{tabular}

\footnotetext{
$\mathbf{R}=$ right coronary artery, $\mathrm{L}=$ left anterior descending coronary artery, $\mathrm{C}=$ left circumflex coronary artery, $M=$ intramural artery. - $=000$ has never been reported clinically but theoretically is a possible orifice configuration. $t=+$ designates that two major coronary branches come off a main branch.

$\mathbf{I}=$ if a major coronary artery (R, $\mathbf{L}$ or $\mathbf{C}$ ) or if a main branch (ie.. $\mathbf{C}+\mathbf{L}, \mathbf{R}+\mathbf{L}$ or $\mathbf{R}+\mathbf{C}$ ) go directly to the atrioventricular or intraventricular groove, course designation is assigned to the branch after the main branch(es) take their variant course.

$A=$ anterior, $P=$ posterior, $B=$ between the aorta and pulmonary trunk, $M=$ intramural
}

arteries within one sinus, even in the presence of dual sinusal origin, can complicate transfer of the coronary arteries.

\section{Proposed surgical classification}

The implication that every coronary artery can be surgically transferred is, to our minds, over simplified.

\section{Dual Sinus Origin}

DS, rhs, $0, R /$ /hs, $0, C+L$

$D S$, rhs, $0, R+C, R, C(P) /$ ihs, $0, L$

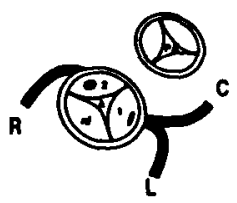

$$
\text { SS, rhs, } \infty, R, C+L(P) C, L
$$

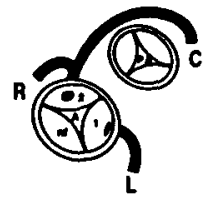

$S S$, rhs, $\infty, R, C+L(B) C, L$

All classifications have been either incomplete or overly complex as to be nearly impossible to describe without a text at hand for an explanation of the anatomical variations.

We have now devised a simplified and complete method of categorization of coronary arterial patterns. It relates the arterial trunks to the origin, pattern of branching, and course of the major coronary arteries.

\section{Single Sinus Origin}

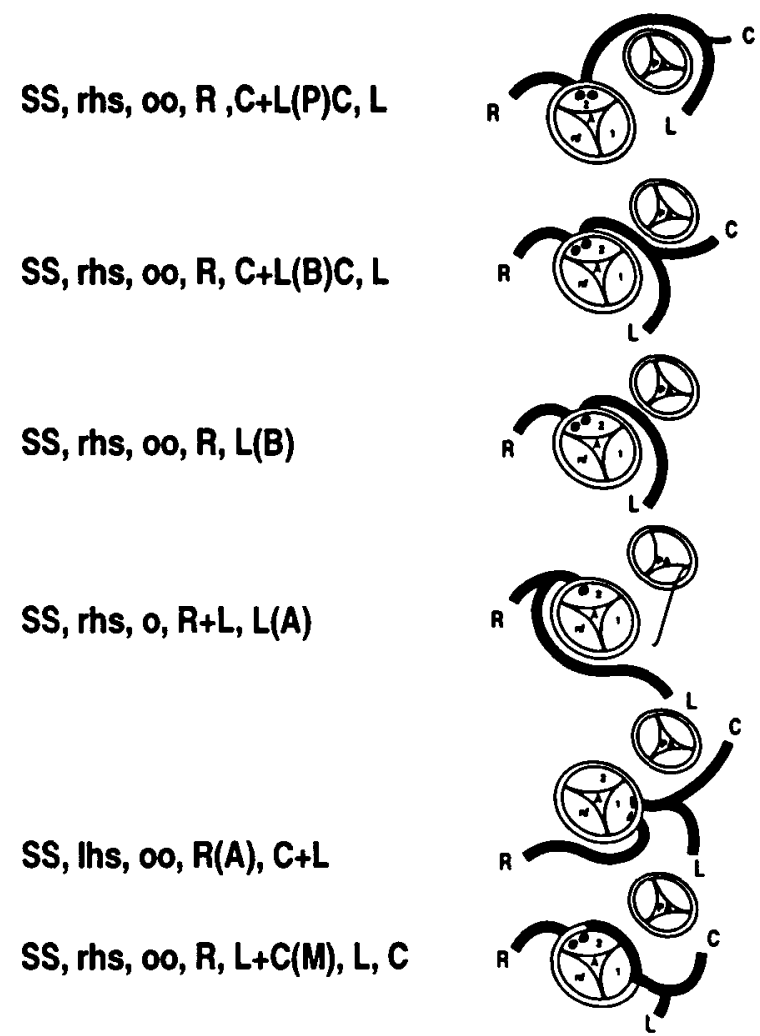

Figure 10. Examples of the Amato classification. SS: single sinus; DS: double sinus; lhs: left-hand sinus; rhs: right hand sinus; $n$ hs: no hand sinus; o: single orifice; oo: double orifice; $R$ : right coronary artery; $L$ : left anterior descending coronary artery; $C$ : left circumflex coronary artery; M: intramural artery. 
Five relational categories are proposed (Table).

\section{Sinus configuration}

Coronary arteries arise from either dual or solitary sinuses. These options can be shortened to "DS" (dual sinus) and "SS" (single or solitary sinus). The coronary arteries, nonetheless, can theoretically arise from any or all of the aortic sinuses (Table).

\section{Sinus location}

Designation of the sinus of origin for each of the major coronary arteries should be determined. The sinuses are identified as left-hand facing (lhf), right-handed facing (rhf), or no-hand sinus (nhs). As already discussed, we prefer to identify the sinuses from the perspective of the observer sitting in or on the pulmonary trunk and looking towards the aorta (Figure 2) (Table).

\section{Orifice configuration}

The number of orifices within the given aortic sinus must also be determined. The options are a single orifice (o), a double orifice (oo), or a triple orifice (ooo). Triple orifice has never been seen clinically but is mentioned here as a possible option (Table).

\section{Coronary arterial branching}

The main coronary arteries are designated right $(\mathrm{R})$, left anterior descending (L), or left circumflex (C), or combinations of two of these arteries. If a main branch takes origin and divides into two major branches, it will be designated with a "+" sign (in other words, if the left main branch divides into the left anterior descending and the left circumflex then it would be designated as $(\mathrm{L}+\mathrm{C})($ Table).

\section{Coronary arterial course}

The course is determined in relation to the main arterial trunks. The options in this category are for any of the major coronary arteries to pass anterior to an arterial outflow tract $(\mathrm{A})$, pass posterior to the arterial pedicles $(\mathrm{P})$, pass between the origins of the aorta and the pulmonary trunk (B), or to take an intramural course (M) (Table). Most coronary arteries go directly to the appropriate interventricular or atrioventricular groove. The course, therefore, is neither anterior nor posterior. When this is the case, no designation of the course is given unless a major branch is given off which then changes the course of that branch.

When this convention is applied to the most common pattern of the coronary arteries observed in complete transposition, the arrangement is conveniently reduced to: $\mathrm{DS}$, rhs o $\mathrm{R} / \mathrm{lhs}$ o $(\mathrm{L}+\mathrm{C})$. This translates to: Dual sinus; right-hand sinus with a single orifice giving rise to the right coronary artery/left-hand sinus with a single orifice giving rise to left anterior descending and circumflex coronary arteries. Additional illustrations and examples are shown in Figure 10.

\section{Conclusion}

With the convention described above, it is possible to describe all coronary arterial patterns. The technical maneuvers are already available which permit the surgeon to cope with all these complex patterns and none, therefore, should deter one from the switch operation. ${ }^{33}$ All authors, nonetheless, have described early mortality secondary to complex coronary arterial anatomy. . $3-6,49-52^{-}$ Should the issue of coronary arteries be considered, a "risk" factor? Kurosawa et a ${ }^{49}$ rightly argued that, since the success of the arterial switch is dependent on the successful translocation of the coronary artery, a thorough understanding of the anatomic variability is essential. Mee ${ }^{50}$ has stated that the arterial switch is a difficult surgical procedure in which the learning curve has been longer and more hazardous than for the atrial procedures.

We believe that there are two learning curves for the arterial switch procedure. The early learning curve is quickly achieved by all surgeons who attempt the procedure. The second learning curve, with which we are all still involved, is the appropriate transfer of the "wraparound" circumflex artery, the coronary arterial systems originating from a single orifice or sinus, and the intramural coronary artery. There are surgeons who will abandon the switch operation when one of these difficult coronary arterial patterns is discovered. Since these situations occur infrequently, no one surgeon has accumulated a statistically significant series.

In conclusion, therefore, we believe that an easier classification is needed for description of all those complex patterns which are encountered clinically. We have proposed such an approach in this review. This knowledge, coupled with use of varied techniques already described, ${ }^{33}$ should assist in the management of these difficult patterns. If properly recognized and managed, we submit that these complex patterns, such as the single coronary artery and the intramural artery, render the switch operation technically difficult but do not represent a contraindication to the procedure.

\section{References}

1. Quagebeur JM, Rohmer J, Ottenkamp J, Buis T, Kirklin JW, Blackstone EH, Brom AG. The arterial switch operation. An eight-year experience. J Thorac Cardiovasc Surg 1986; 92: 361-384.

2. Kirklin JW. The surgical repair for complete transposition. Cardiol Young 1991; 1: 13-25.

3. Norwood W, Dobell A, Freed M, Kirklin JW, Blackstone E, 
and the Congenital Heart Surgeons Society. Intermediate results of the arterial switch repair. J Thorac Cardiovasc Surg 1988; 96: 854-863.

4. Castañeda AR, Norwood WI, Jonas RA, Colon SD, Sanders SP, Lang P. Transposition of the great arteries and intact ventricular septum: anatomical repair in the neonate. Ann Thorac Surg 1984; 38: 438-443.

5. Planché C, Bruniaux J, Lacour-Gayet F. Switch operation for transposition of the great arteries in neonates: a study of 120 patients. J Thorac Cardiovasc Surg 1988; 96: 354-363.

6. Day RW, Laks H, Drinkwater DC. The influence of coronary anatomy on the arterial switch operation in neonates. J Thorac Cardiovasc Surg 1992; 104: 706-712.

7. Yamaguchi M, Hosokawa $Y$, Imai $Y$, Kurosawa $H$, Yasui $H$, Yagihara T, Okamoto F, Wakaki N. Early and mid-term results of the arterial switch operation for transposition of the great arteries in Japan.J Thorac Cardiovasc Surg 1990; 100:261-269.

8. Mayer JE, Sanders SP, Jonas RA, Castañeda AR, Wernovsky G. Coronary artery pattern and outcome of arterial switch operation for transposition of the great arteries. Circulation 1990; 82(Suppl IV): IV 139-IV 145

9. Blalock A, Hanlon CR. The surgical treatment of complete transposition of the aorta and the pulmonary arteries. Surg Gynec Obst 1950; 90: 1-15.

10. Bailey CP, Cookson BA, Downing DF, Neptune WB. Cardiac surgery under hypothermia. J Thorac Cardiovasc Surg 1954; 28: 229-235.

11. Mustard W'T, Chute AL, Keith JD, Sirek A, Rowe RD, Vlad P. A surgical approach to transposition of the great vessels with extracorporeal circuit. Surgery 1954; 36: 39-51.

12. Kay EB, Cross FS. Surgical treatment of transposition of the great vessels. Surgery 1955; 38: 712-716.

13. Senning A. Surgical correction of transposition of the great arteries. Surgery 1959; 45: 966-980.

14. Bjork VO, Bouckaert L. Complete transposition of the aorta and pulmonary artery. An experimental study of the surgical possibilities for its treatment. J Thorac Surg 1954; 28: 632635

15. Bex JP, Lecompte Y, Baillot F, Hazan E. Anatomical correction of transposition of the great arteries. Ann Thorac Surg 1990; $29: 86-89$.

16. Idriss FS, Goldstein IR, Grana L, French D, Potts WJ. A new technique for complete correction of transposition of the great vessels: an experimental study with a preliminary clinical report. Circulation 1961; 24: 5-11.

17. Anagnostopoulos CE. A proposed new technique for correction of transposition of the great arteries. Ann Thorac Surg 1973; 15: 565-569.

18. Anagnostopoulos CE, Athanasuleas CL, Arcilla RA. Toward a rational operation for transposition of the great arteries. Ann Thorac Surg 1973; 16: 458-463.

19. Balderman SC, Athanasuleas AB, Anagnostopoulos CE. Coronary artery anatomy in transposition of the great vessels in relation to anatomic surgical correction. J Thorac Cardiovasc Surg 1974; 67: 208-212.

20. Jatene AD, Fontes VF, Paulista PP, Souza LCB, Neger F, Galantier M, Sousa JE. Successful anatomic correction of transposition of the great vessels. A preliminary report. Arg Braz Cardiol 1975; 28: 461-465.

21. Damus P. Letter to the editor. Ann Thorac Surg 1975; 20: 724-725.

22. Kaye MP. Anatomic correction of transposition of great arteries. Mayo Clin Proc 1975; 50: 638-640.

23. Stansel HC Jr. A new operation for a d-loop transposition of the great vessels. Ann Thorac Surg 1975; 19: 565-567.
24. Danielson GK, Tabry IF, Mair DD, Fulton RE. Great vessel switch operation without coronary relocation for transposition of great arteries. Mayo Clin Proc 1978; 53: 675-682.

25. Aubert J, Pannetier A, Couvelly JP, Unal D, Rouault F, DeLarue A. Transposition of the great arteries: new technique for anatomical correction. Br Heart J 1978; 40: 204-208.

26. Abe T, Kuribayashi R, Sato M. Successful Jatene operation for transposition of the great arteries with intact ventricular septum-a case report. J Thorac Cardiovasc Surg 1978; 75: 64-68.

27. Mauck HP Jr, Robertson LW, Parr EL, Lower RR. Anatomic correction of transposition of the great arteries without signifcant ventricular septal defect or patent ductus arteriosus. J Thorac Cardiovasc Surg 1977; 74: 631-634.

28. Yacoub MH, Radley-Smith R, MacLaurin R. Two-stage operation for anatomical correction of transposition of the great arteries with intact ventricular septum. Lancet 1977; 1: $1275-1278$.

29. Radley-Smith R, Yacoub MH. One-stage anatomic correction of simple transposition of the great arteries in neonates. Circulation 1984; 70(Suppl II): II 121. [Abstract]

30. Lecompte Y, Zannini L, Hazan E, Jarreau MM, Bex JP, Tu TV, Neveux JY. Anatomic correction of transposition of the great arteries: new technique without use of a prosthetic conduit. J Thorac Cardiovasc Surg 1981; 82: 629-631.

31. Driscoll DJ. Congenital coronary artery anomalies. In: Carson A, Bricker TJ, McNamara DG (eds). The Science and Practice of Pediatric Cardiology, Vol. 2. Lea and Febiger, Philadelphia/ London 1990, pp 1453-1461.

32. Gittenberger-de Groot AC, Sauer U, Oppenheimer-Dekker A, Quaeqebeur J. Coronary arterial anatomy in transposition of the great arteries: a morphologic study. Pediatr Cardiol 1983; 4(Suppl 1): 15-24.

33. Amato JJ, Galdieri RJ. The arterial switch: surgical technique in respect to coronary artery patterns. In: D'Alessandro LC (ed). Heart Surgery 1991. Casa Editrice Scientifica Internazionale, Rome, 1991, pp 237-248.

34. Elliott LP, Neufeld HN, Anderson RC, Adams PJ, Edwards JE. Complete transposition of the great vessels. An anatomic study of 60 cases. Circulation 1963; 27: 1105-1117.

35. Planché C, Serraf A, Lacour-Gayet F, Bruniaux J, Touchart F. Anatomic correction of complete transposition with ventricular septal defect in neonates: experience with 42 consecutive cases. Cardiol Young 1991; 1: 101-103.

36. Massumi GA, Hall RJ. Selective coronary arteriography in children with heart disease. In: Carson A, Bricker TJ, McNamary DG (eds). The Science and Practice of Pediatric Cardiology, Vol. 1. Lea and Febiger, Philadelphia/London 1990, pp 968-972.

37. Arensman FW, Sievers HH, Lange P, Radley-Smith R, Bernhard MD, Heintzen P, Yacoub MH. Assessment of coronary and aortic anastomosis after anatomical correction of transposition of the great arteries. J Thorac Cardiovasc Surg 1985; 90: 597-604

38. Bierman FZ, Williams RG. Prospective diagnosis of d-transposition of the great arteries in neonates by subxyphoid twodimensional echocardiopgrahy. Circulation 1979; 60: 14961502.

39. Rigby ML, Chan KY. The diagnostic evaluation of patients with complete transposition. Cardiol Young 1991; 1: 26-40.

40. Shaher RM, Puddu CG. Coronary artery arterial anatomy in complete transposition of the great vessels. Am J Cardiol 1966; 17: 355-362.

41. Yacoub MH, Radley-Smith R. Anatomy of the coronary arteries in transposition of the great arteries and methods for 
their transfer in anatomical correction. Thorax 1978; 33:418424

42. Rowlatt UF. Coronary artery distribution in complete transposition. J Am Med Assoc 1962; 178: 269-278.

43. Smith A, Arnold R, Wilkinson JL, Hamilton DI, McKay R, Anderson RH. An anatomical study of the patterns of the coronary arteries and sinus nodal artery in complete transposition. Int J Cardiol 1986; 12: 295-304.

44. Gittenberger-de Groot A. Elucidating coronary arterial anatomy or simplifying coronary arterial nomenclature. Int J Cardiol 1986; 12: 305-307.

45. Kirklin JW. Arterial switch operation. Letter from the editor. J Thorac Cardiovasc Surg 1990; 100: 314.

46. Yamaguchi M. Arterial switch operation. Reply to the editor. J Thorac Cardiovasc Surg 1990; 100: 314.

47. Wilcox BR, Anderson RH. Surgical Anatomy of the Heart, 2nd Edition. Gower Medical Publishing, London, New York, $1992, \mathrm{p} 4.2$

48. Anderson RH. Personal communication, January 21, 1994.

49. Kurosawa H, Imai V, 'Takanashi Y, Hoshino S, Sawatari K Kawoda M, Takao A. J Thorac Cardiovasc Surg 1986; 91: 572-583.

50. Mee RBB. Results of the arterial switch procedure for complete transposition with an intact septum. Cardiol Young 1991; 1: 97-98.

51. Serraf A, Lacour-Gayet F, Bruniaux J, Touchot A, Losay J, Comas J, Uva MS, Planché C. Anatomic correction of transposition of the great arteries. J Am Coll Cardiol 1993; 193200.

52. Kurosawa H, Imai Y, Kawada M. Coronary arterial anatomy in regard to the arterial switch procedures. Cardiol Young 1991; 1: 54-62. 